\title{
Article
}

\section{The Critical Indicator of Red-Bed Soft Rocks in Deterioration Process Induced by Water Basing on Renormalization Group Theory}

\author{
Chang Xia ${ }^{1,2,3}$, Cuiying Zhou ${ }^{1,2,3, *}$, Fengxian Zhu ${ }^{1,2,3}$, Zhen Liu 1,2,3,*(D) and Guangjun Cui ${ }^{1,2,3}$ \\ 1 School of Civil Engineering, Sun Yat-Sen University, Zhuhai 519082, China; xiach9@mail2.sysu.edu.cn (C.X.); \\ ueit@mail.sysu.edu.cn (F.Z.); cuigj3@mail2.sysu.edu.cn (G.C.) \\ 2 Guangdong Engineering Research Centre for Major Infrastructures Safety, Guangzhou 510275, China \\ 3 Research Center for Geotechnical Engineering and Information Technology, Sun Yat-Sen University, \\ Guangzhou 510275, China \\ * Correspondence: zhoucy@mail.sysu.edu.cn (C.Z.); liuzh8@mail.sysu.edu.cn (Z.L.)
}

check for

updates

Citation: Xia, C.; Zhou, C.; Zhu, F.; Liu, Z.; Cui, G. The Critical Indicator of Red-Bed Soft Rocks in

Deterioration Process Induced by Water Basing on Renormalization Group Theory. Appl. Sci. 2021, 11, 7968. https://doi.org/10.3390/ app11177968

Academic Editor: Giuseppe Lacidogna

Received: 9 August 2021

Accepted: 25 August 2021

Published: 28 August 2021

Publisher's Note: MDPI stays neutral with regard to jurisdictional claims in published maps and institutional affiliations.

Copyright: (c) 2021 by the authors. Licensee MDPI, Basel, Switzerland. This article is an open access article distributed under the terms and conditions of the Creative Commons Attribution (CC BY) license (https:// creativecommons.org/licenses/by/ $4.0 /)$.

\begin{abstract}
The internal damage of red-bed soft rock induced by water is pervasive. The accumulation, growth, and localization of damage is a multi-scale process that can lead to significant strength loss in red-bed soft rock. Yet, research on the critical state of deterioration process considering multi-scale failure is limited due to high degree of system freedom. Renormalization group theory is an effective approach to find critical point of phase transition in a disordered system. To apply renormalization group theory in red-bed soft rocks, this article firstly analyzed their microstructures. Then, the granular unit model and stripy unit model are proposed to describe the self-similar characteristics of red-bed soft rocks. The calculation results based on renormalization group theory are consistent with the experimental results. The critical reductions of strength induced by water are $60 \%$ in lightyellow silty mudstone and $80 \%$ in grey silty mudstone. In addition, the critical state of damage propagation caused by stress is also studied and the analytical solution is derived. Results show that the renormalization group theory can effectively couple the micro damage and strength deterioration which provides guidance to the engineering.
\end{abstract}

Keywords: red-bed soft rock; renormalization group theory; critical state; microstructure

\section{Introduction}

Red clastic rocks weathered in laterite from the Mesozoic-Cenozoic era is termed "red-bed" [1]. The red bed mainly incorporates lacustrine deposits, fluvial facies deposits, and piedmont diluvial deposits. Moreover, the red bed is primarily composed of mudstone, sandstone, siltstone and shale. Figure 1 shows the state of red-bed soft rock in different scales. Normally, the meso-structure of red-bed soft rock shows discontinuity and anisotropy [2] caused by original defects (e.g., pores and cracks) [3]. Meanwhile, the red-bed soft rocks are rich in clay mineral (e.g., montmorillonite and kaolinite) which is sensitive to hydration-induced damage [4]. Hence, the special characteristics of red-bed soft rocks occasionally bring engineering disasters [5-9] (e.g., structure collapse in deep soft rock tunnel, slope slide, water infiltration induced deterioration, and creep induced large deformation problems). The study on deterioration mechanism is important to academic research and also the engineering guidance. However, the above-mentioned factors make it difficult to study the failure process in a precise way. In addition, the water induced failure propagation in red-bed engineering is regarded as a multi-scale issue [10], including the dissolution and slide of clay minerals in meso-scale, the crack propagation and coalescence in meso-scale, and the strength deterioration in macro-scale. Dealing with such a complex process, we need to find an applicable method. However, researches on the deterioration process in red-bed soft rock are limited either on meso-scale or on macro-scale. 


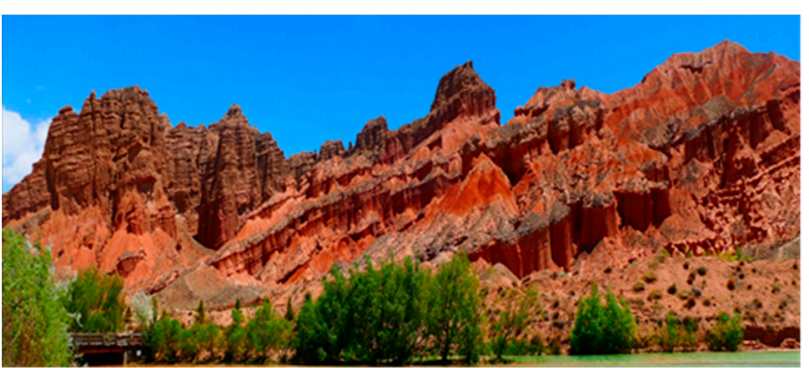

Engineering scale

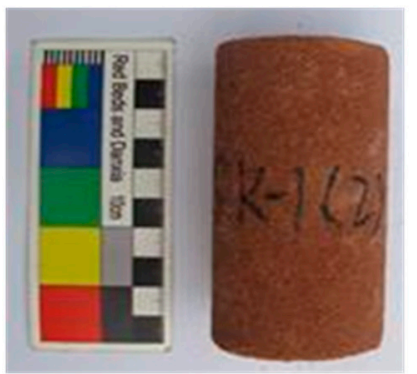

Laboratory scale
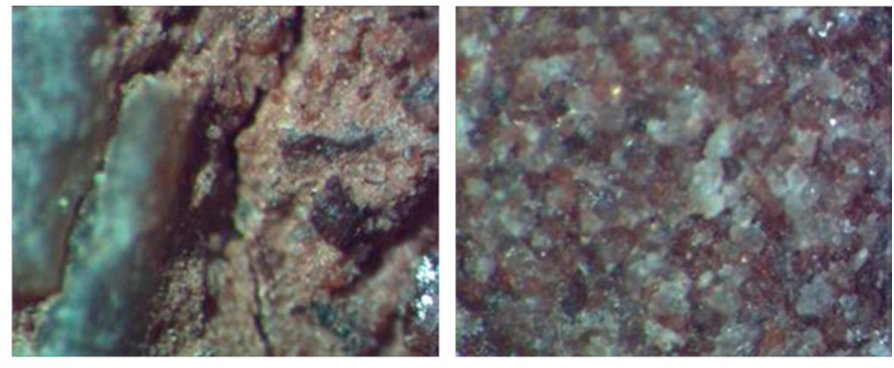

Grain scale
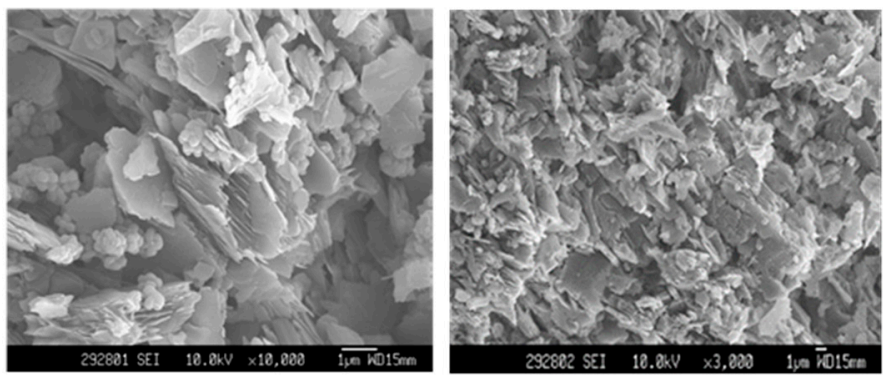

Meso-structure scale

Figure 1. The red-bed soft rock and its properties in multi-scale.

Nowadays, the researches of red-bed soft rock's failure process mainly involved in triaxial tests under ultimate environments and meso-mechanical analysis basing on image technologies. On the one hand, basing on mechanical experiments, Palchik et al. [11] studied the influence of micro parameters, (including porosity, particle radius, elastic modulus), on the strength of porous sandstone. Yu et al. [12] proposed a stress-strain relation that is more applicable to porous soft rock by uniaxial and triaxial tests. Lollino et al. [13] studied the pre-peak mechanical behavior of red-bed soft rock through loading, tensile, and shear tests under low confining pressures. Meanwhile, many scholars have studied the failure mechanisms of red-bed soft rock considering water corrosion [14-20]. When red-bed soft rocks encountering poor engineering conditions, Leuthold et al. [21] conducted triaxial tests of porous soft rock under dry and wet environments to obtain the law of permeability variation and shear zone distribution. Jiang et al. studied the shear mechanisms of red-bed soft rock through shear test and CT analysis [22]. On the other hand, basing on the image technology, many researches of SEM [23,24] (Scanning Electron Microscope), AE [25,26] (Acoustic Emission), CT [2,27] (Computed Tomography) are carried out. Komine et al. [28] found that the red-bed soft rocks generally develop various micro-defects around the clay mineral aggregations, and studied the expansion mechanism during the water immersion process. Arnould et al. [29] analyzed the disintegration mechanisms of mudstone from the perspective of mineral composition, and proposed a discontinuous network model. Risnes et al. [30] studied the effects of water corrosion mechanisms on the micro-scale of soft rocks. In general, these researches are limited in macro-mechanical deterioration or meso-structure damage analysis. However, we may want to know more about the relation between meso-damage and macro-failure in the damage evolution process. In addition, the critical point that separate the stable state and unstable state is also necessary to be predicted which is quite important to the engineering guidance.

Note that, the water induced deterioration is a phase transition process (from stable phase to unstable phase). In a previous study, many similar works have been done to deal with rock's phase transition process rely on renormalization group theory. Xue et al. [31] have studied the stress induced failure evolution in hard rock, and gave a solution to predict the volume strain reverse point in stress-strain curve. Xue et al. [32] also studied the continuous progressive deformation in soft rock slopes, and they pick the deformation ratio as an indicator of the damage propagation process. Jiang et al. [33] established the connection between damage and unloading time in excavation induced rock failure. 
Wei [34] and Iranyani [35] et al. studied the anisotropy permeability in porous rock and gave the estimation method rely on renormalization group theory. The above-mentioned works provide an insight for dealing with the water induced deterioration process in red-bed soft rocks.

Therefore, the unit models of red-bed soft rocks are established by SEM experiments in this paper, and the multi-scale analysis is accomplished through basing on the renormalization group theory $[31,36,37]$. The critical strength reduction coefficients of red-bed soft rocks are calculated and verified by experiments.

\section{Materials and Methods}

\subsection{The Meso-Structures of Red-Bed Soft Rocks and the Corresponding Unit Models}

It can be found from Figure 2 that the red-bed soft rock is rich in clay minerals which are arranged in disordered way, showing a flocculent state. Pores are uniformly distributed between clay minerals. These aggregated clay minerals are composed of some smaller particles with a few microns in diameter. In detail, these aggregated particles resemble polygon flakes, and show surface-to-surface contact or point-to-surface contact, forming continuous and disordered thin layers. Then, these thin layers are stacked in parallel. Considering the above-mentioned characteristics, Tuller et al. [36] provide a good inspiration of building clay unit models of red-bed soft rock.

Based on the model proposed by Tuller et al., the elements simplified model of red-bed soft rock is shown in Figure 2, including a granular element and a stripy element. The granular element acts the skeleton role and stripy element acts the cementation role which is composed of clay minerals. When immersed, the stripy elements will absorb water which can cause expansion and damage. These multi-scale damages are complicated. Some damages that cause the meso-structure's failure are termed important information in renormalization process while some damages won't weaken the capacity of soft rock are termed secondary information. The critical state to the red-bed deterioration process can be derived after steps of renormalizing important information.

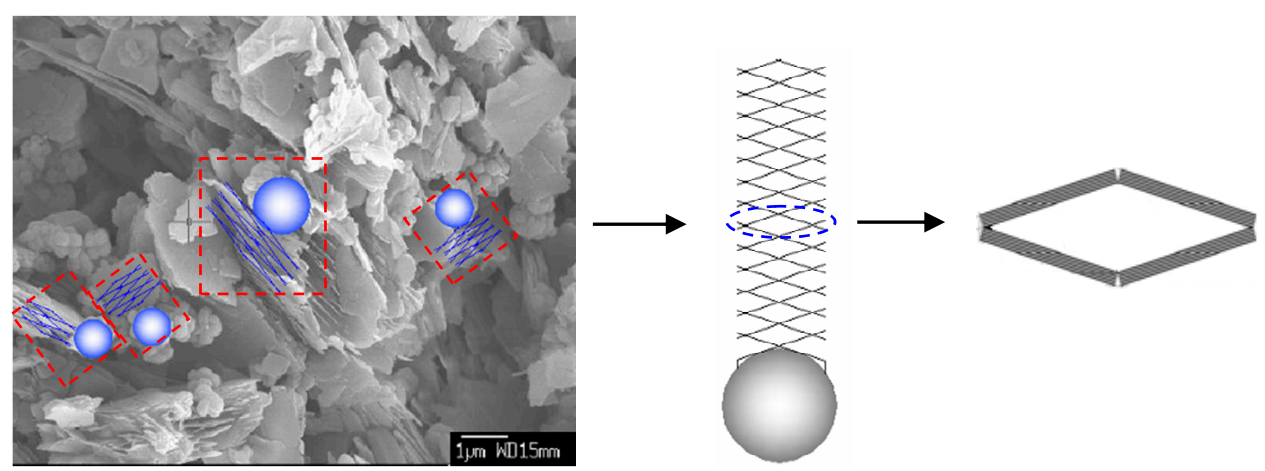

Figure 2. The mineral elements of red-bed soft rock [38].

When applying the elements in Figure 2 into renormalization group analysis, two kinds of unit models are proposed. In Figure $3 a$, we define that the granular elements and stripy elements showing a ratio of 1:1 is termed granular model. In Figure $3 b$, the granular elements and stripy elements showing a ratio of 1:4 is termed stripy model. Subsequently, two kinds of renormalization group models can be established. 


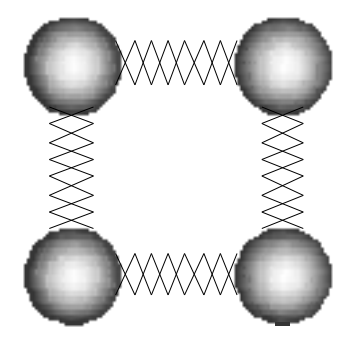

(a)

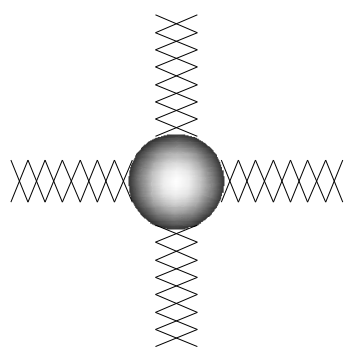

(b)

Figure 3. Two kinds of unit models of red bed soft rocks. (a) Granular model; (b) Stripy model.

\subsubsection{The Renormalization Model Basing on Granular Model}

In granular structure, the ratio of clay mineral and skeleton mineral is 1:1. Considering this ratio, we pick four mineral elements and four granular elements to compose one granular renormalization unit model. This kind of soft rock is rich in quartz particles and shows a shape of dense granular structure. The clay mineral layers are arranged between skeleton particles.

In this unit model, four granular elements in the corner are important to the stability of unit and the clay minerals that cement skeleton minerals are prone to be affected by water causing bonds failure. Basing on the abovementioned structures, the renormalization group model is proposed showing in Figure 4. According to the self-similar characteristics of red-bed soft rock, the granular structure can be observed in different scales. The unit model in a higher scale can be decomposed to some smaller unit models in the minor scale.

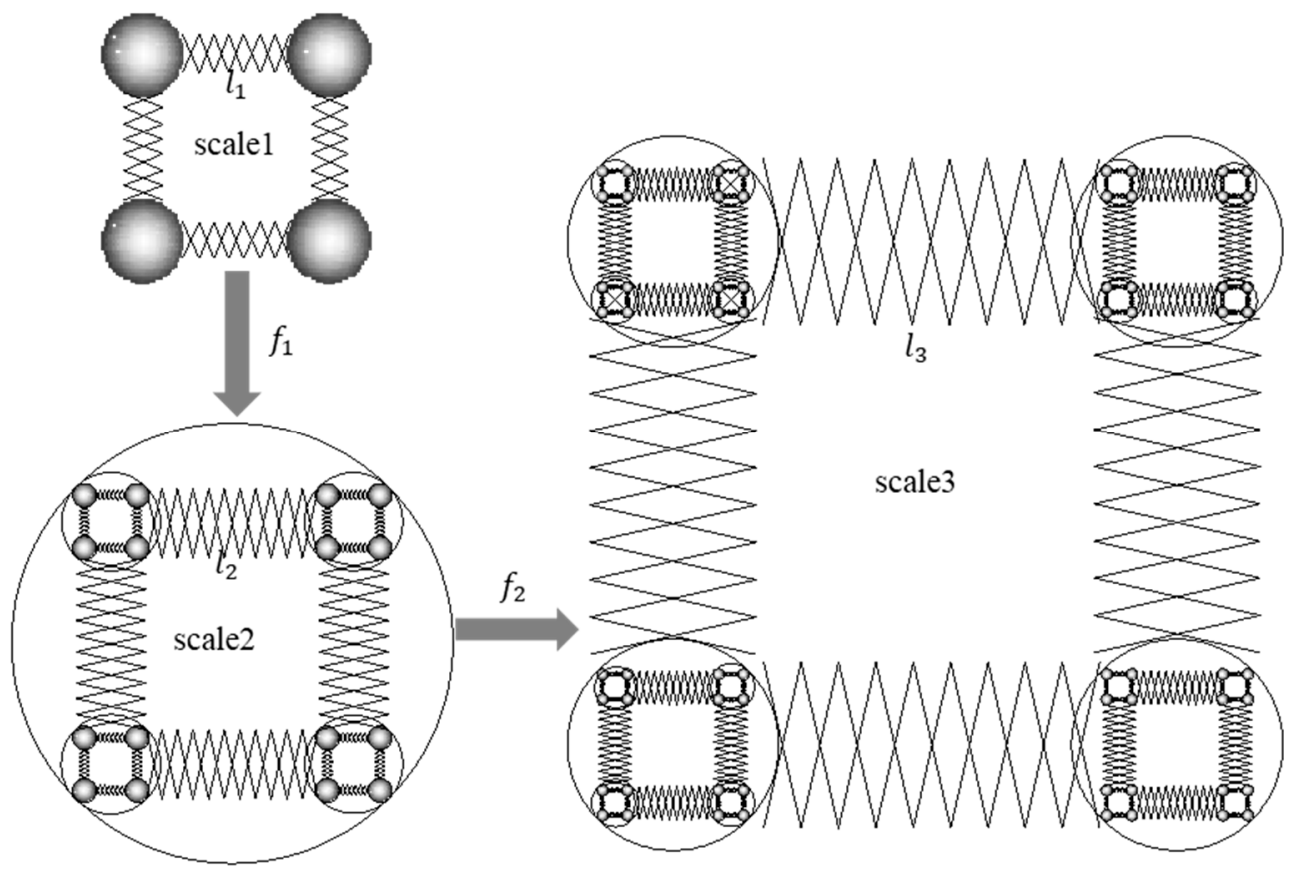

Figure 4. The renormalization model of granular unit.

\subsubsection{The Renormalization Model Basing on Stripy Model}

In the stripy model, the ratio of clay mineral and skeleton mineral is 4:1. Considering this kind of mineral ratio, we pick four mineral elements and one granular element to compose one stripy renormalization unit. This kind of soft rock is rich in clay minerals and shows a shape of dense stripy structure.

In this unit model, due to high ratio of clay minerals, the model is more likely to be broken in water. The skeleton elements in the center support the red-bed soft rock system. Basing on the stripy model, we established the renormalization model in Figure 5. 
According to the self-similar characteristics of red-bed soft rock, the stripy unit model can be observed in different scales and the unit model in higher scale can be decomposed into some smaller unit models in the minor scale.

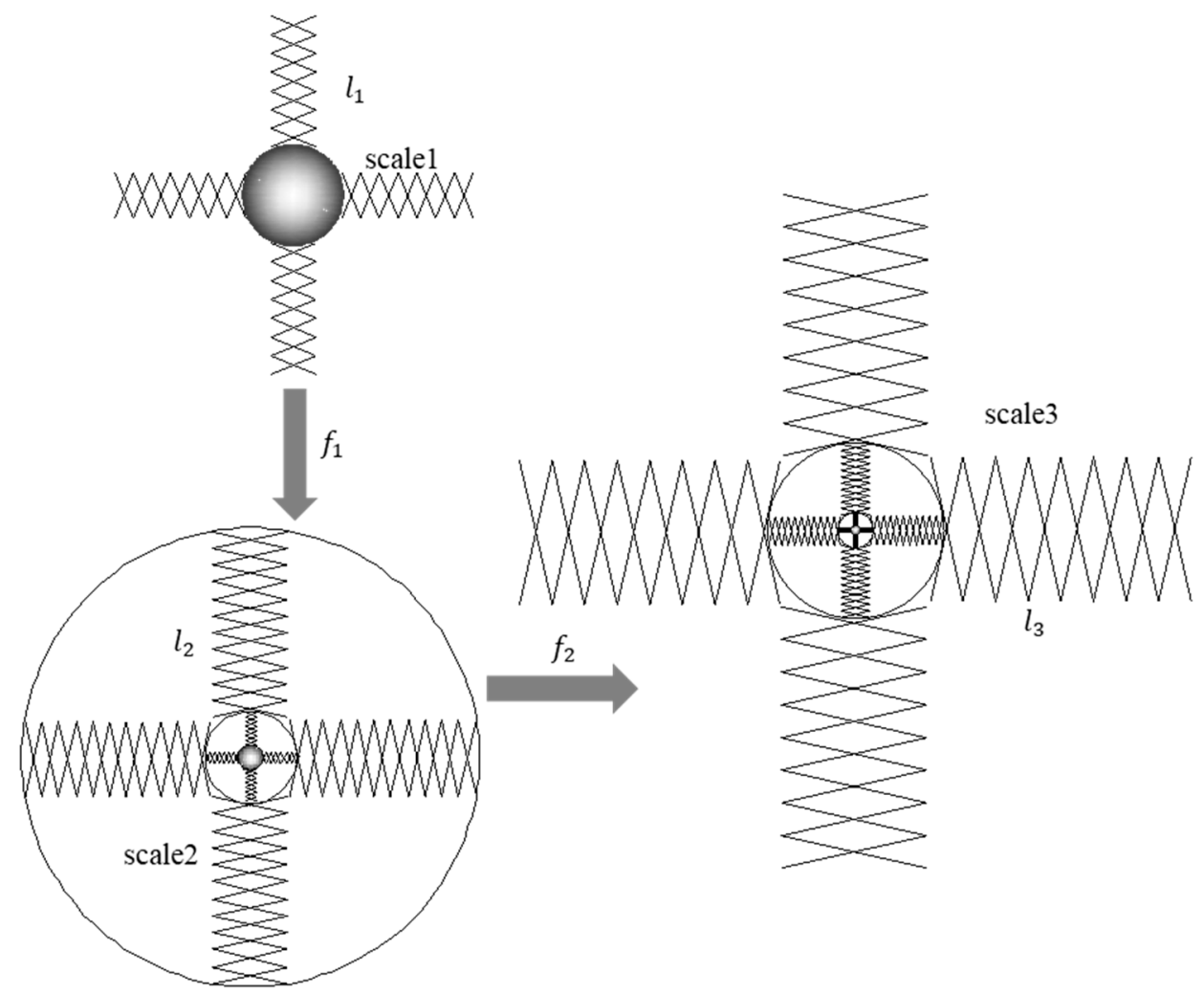

Figure 5. The renormalization model of stripy unit.

The damage process can be found in different scales, and these damages appear in minor scale can be accumulated into the next scale in renormalization progress. Some damage will cause the unit model to fail and subsequently affect the stability of next scale; this damage is termed important information in renormalization group theory. However, some damage will not affect the unit model's function; hence, this kind of damage termed secondary information is ignored in the renormalization process.

The specific renormalization models of red-bed soft rocks need to be analyzed combining the SEM images. The phase transition point of red-bed soft rocks under water immersion caused deterioration can be calculated basing on the specific renormalization models.

\subsection{The Description of Red-Bed Soft Rock Deterioration Process Basing on Renormalization Group Theory}

When a disordered system is self-similar in morphology or statistics, the renormalization group theory can be applied to analyze the critical point in phase transition process. In this article, the multi-scale damage propagation of red-bed soft rock is analyzed by variating the length scale, and the degree of the system is reduced by ignoring the secondary information on micro and minor scales. After steps of renormalization, soft rock system will be simplified and can be calculated easily. When the critical point appears, the important information plays a decisive role, and the secondary information is not important to the final results.

A general description of renormalization group theory shows a physical quantity $T_{1}$ of red-bed soft rock can be obtained at an initial scale $l$. When the scale increasing to $2 l$ by a nonlinear transformation relation $f, T_{1}$ is transformed to $T_{2}$ subsequently:

$$
T_{2}=f\left(T_{1}\right)
$$


If the system is self-similar, the scale can increase from $2 l$ to $3 l$, and the corresponding physical quantity $T_{3}$ is obtained:

$$
T_{3}=f\left(T_{2}\right)=f \cdot f\left(T_{1}\right)=f_{2}\left(T_{1}\right)
$$

where $f_{2}$ represents a twice transformation. Normally, this process satisfies the following rules:

$$
f_{i} \cdot f_{j}=f_{i+j}(i, j=1,2,3 \cdots)
$$

When the scale continue increases, the following relationship is derived:

$$
T_{i+1}=f_{i}\left(T_{1}\right)(i=1,2,3 \cdots)
$$

According to renormalization group theory, there are some critical points in the transformation process such that:

$$
T_{c}=f\left(T_{c}\right)
$$

For a self-similar system, $T_{c}$ is a critical point, which is the deterioration critical state obtained after steps of renormalization process. Figure 6 shows the schematical renormalization process of red-bed soft rock. It can be found that the mineral is prone to be broken under water corrosion, which is a phase transition process from stable to unstable. Noting that, this damage process happens at multi-scale which can be calculated by renormalization group theory.

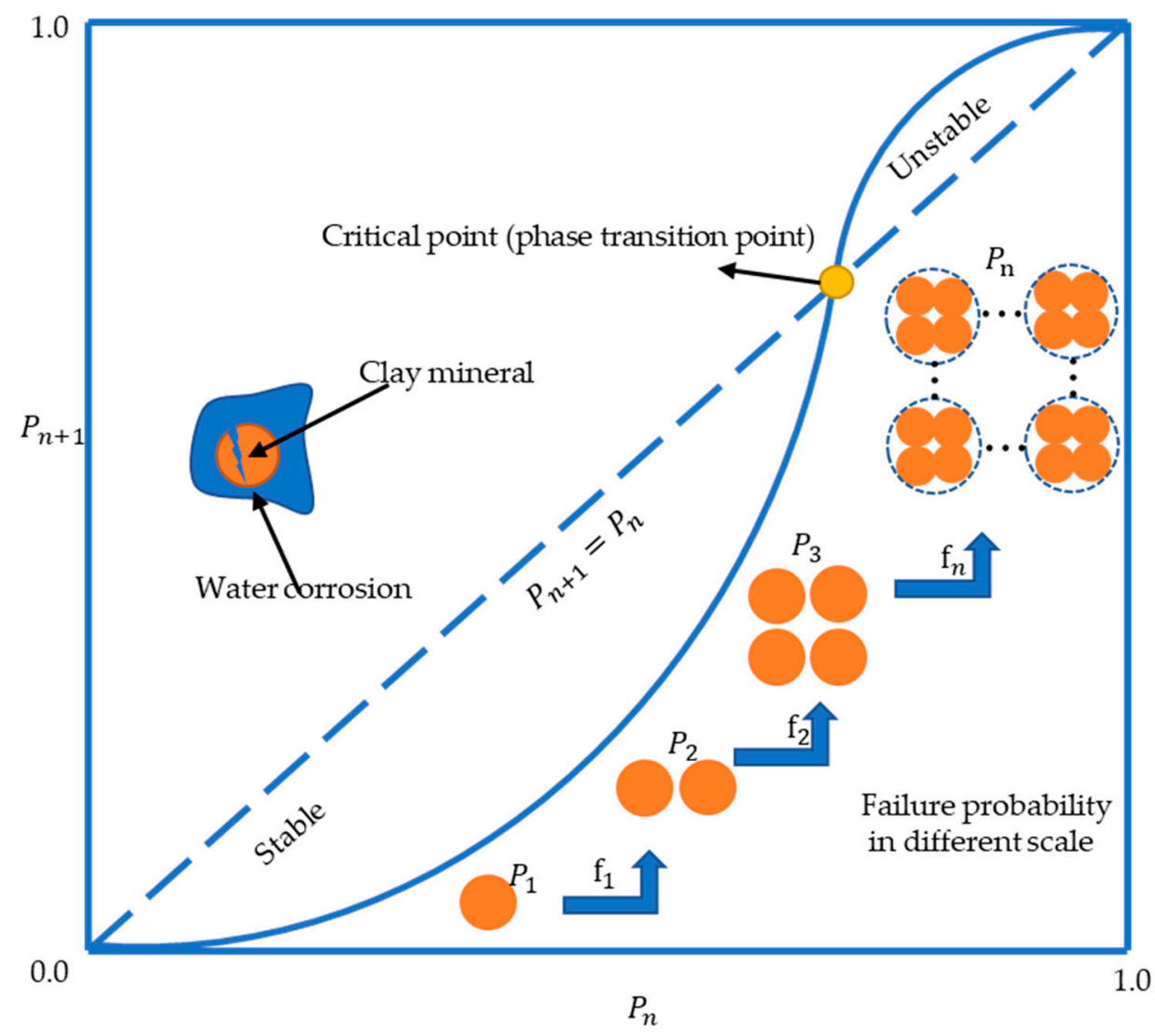

Figure 6. The schematical renormalization process of red-bed soft rock.

\subsection{The Calculation for Critical State of Deterioration Induced by Water}

Before applying renormalization group theory into calculating, we make some assumptions firstly:

(1) The probability of water induced failure in clay mineral is the same. 
(2) The strength reduction coefficient of red-bed soft rock is equivalent to critical failure probability in the renormalization process.

We also give the definition of "strength reduction coefficient":

A: The initial strength of red-bed soft rock.

B: The strength of red-bed soft rock after saturation.

C: Strength reduction coefficient.

$\mathrm{C}=(\mathrm{A}-\mathrm{B}) / \mathrm{A}$ is termed "strength reduction coefficient" in this paper.

\subsubsection{The Calculation Process of Granular Model}

Figure 7 shows the process of applying renormalization group theory in the critical point calculation. In the initial unit model, there are 16 different damage states in Figure 8. The high degree system makes it difficult to solve in a mathematical way. However, according to renormalization group theory, there are only two kinds of information (important and secondary information) in the system. We believe that only two or two more skeleton particles are failing, the unit model's failure will appear. From Figure 8, we can divide these states into two states. The renormalization process accumulates the important information and ignore the secondary information. After many times of iterative renormalization, a critical point can be calculated.

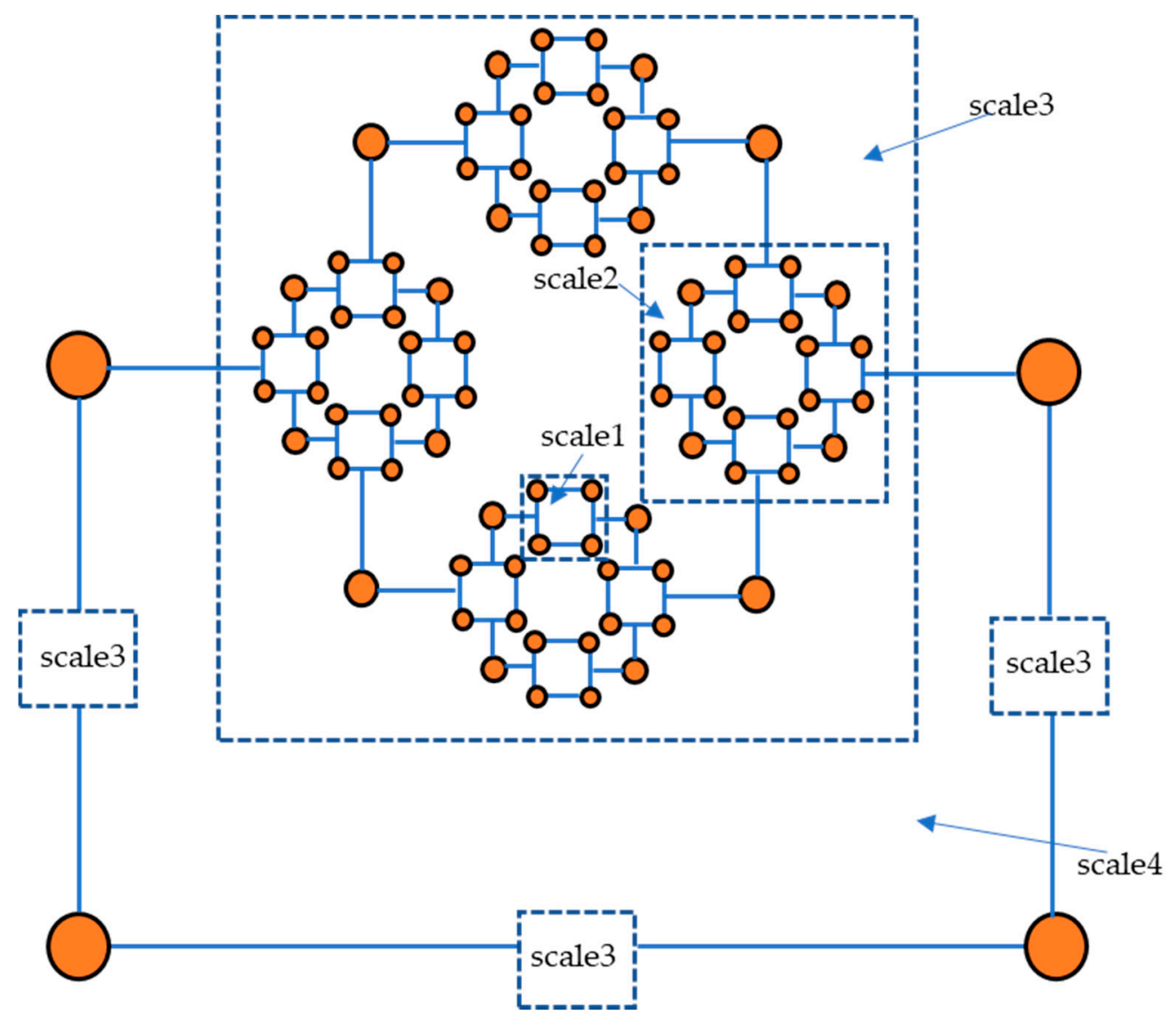

Figure 7. The renormalization process of granular unit models. 


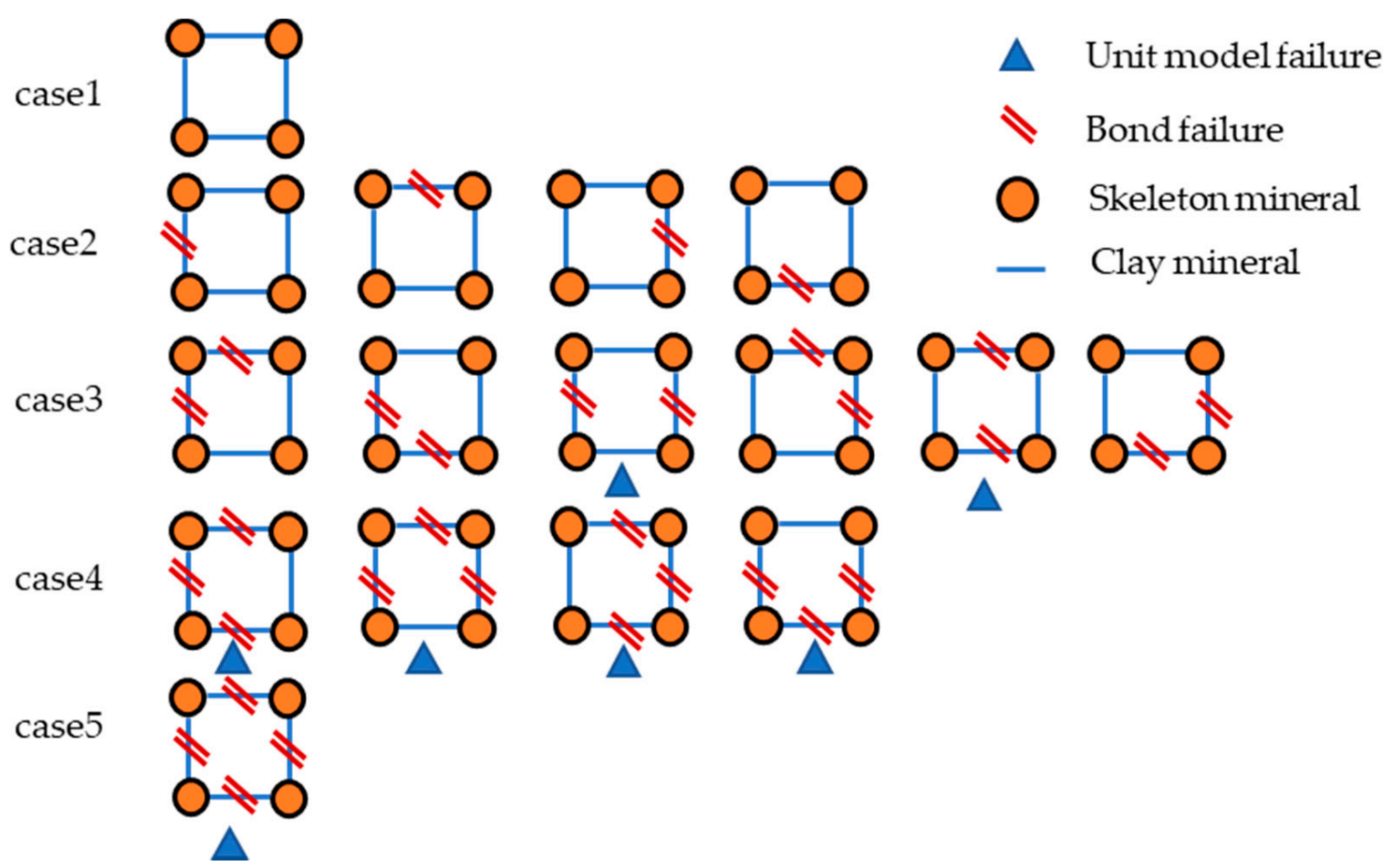

Figure 8. Different state of granular unit models.

We can firstly analyze the failure probability of unit model in the first two scales:

$$
P_{1}=2 P^{2}(1-P)^{2}+4 P^{3}(1-P)+P^{4}
$$

where $P_{1}$ represents the unit failure probability in scale 1 , and $P$ represents the failure probability of mineral elements encountering water immersion. The failure probability in the right side of Equation (6) is derived from the six failure unit model states in Figure 8. According to the renormalization group theory, after one time transformation, the accumulated failure probability in scale 2 is derived:

$$
P_{2}=2 P_{1}^{2}\left(1-P_{1}\right)^{2}+4 P_{1}^{3}\left(1-P_{1}\right)+P_{1}^{4}
$$

After $\mathrm{n}$ times of renormalization, the failure probability of red-bed soft rock in scale $\mathrm{n}$ is derived:

$$
P_{n}=2 P_{n-1}^{2}\left(1-P_{n-1}\right)^{2}+4 P_{n-1}^{3}\left(1-P_{n-1}\right)+P_{n-1}^{4}
$$

According to renormalization group theory, the solution of $P_{n+1}=P_{n}$ is corresponding to the red-bed soft rock critical deterioration state.

According to $P_{n+1}=P_{n}$, we can derive Equation (10):

$$
P_{n}=2 P_{n}^{2}\left(1-P_{n}\right)^{2}+4 P_{n}^{3}\left(1-P_{n}\right)+P_{n}^{4}
$$

Solving this equation, we can obtain 4 solutions $(0,1,-1.6$ and 0.6 respectively). $P_{n}^{*}=0.6$ is the only reasonable solution, and it means that during the renormalization process, the red-bed soft rock with granular model has a critical strength reduction coefficient of 0.6 under long-term water corrosion.

\subsubsection{Calculation Process of the Stripy Model}

Similarly, Figure 9 shows the process of applying renormalization group theory in the critical point calculation of the stripy model. In the initial unit model, there are 15 different damage states in Figure 10. The high degree system makes it difficult to solve in a mathematical way too. According to renormalization group theory, the complex 
information can be simplified to important and secondary information. We believe that only when the skeleton particles are failing, the unit model's failure will appear. According to Figure 10, we can divide these states into two states. The renormalization process accumulates the important information and ignore the secondary information. After many times of iterative renormalization, a critical point can be calculated.

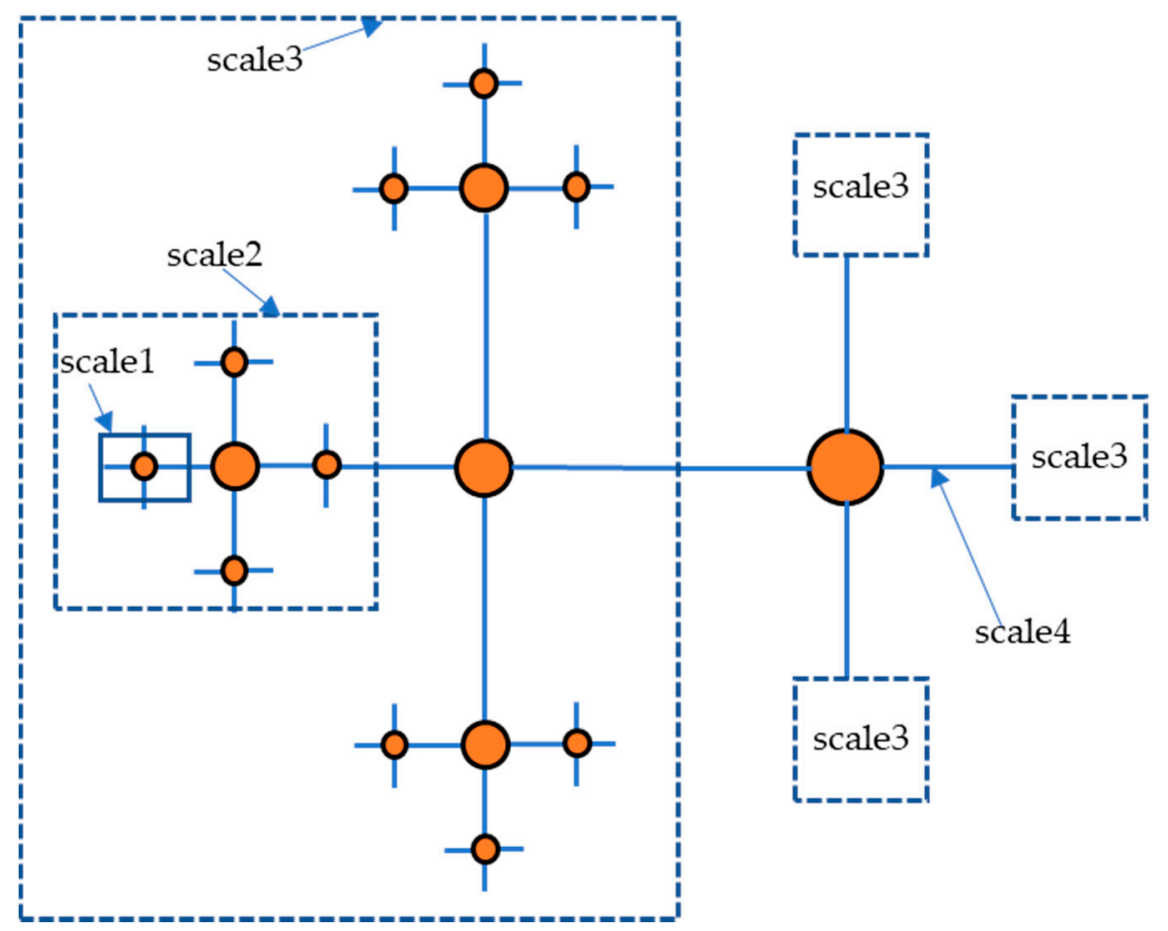

Figure 9. The renormalization process of stripy unit models.
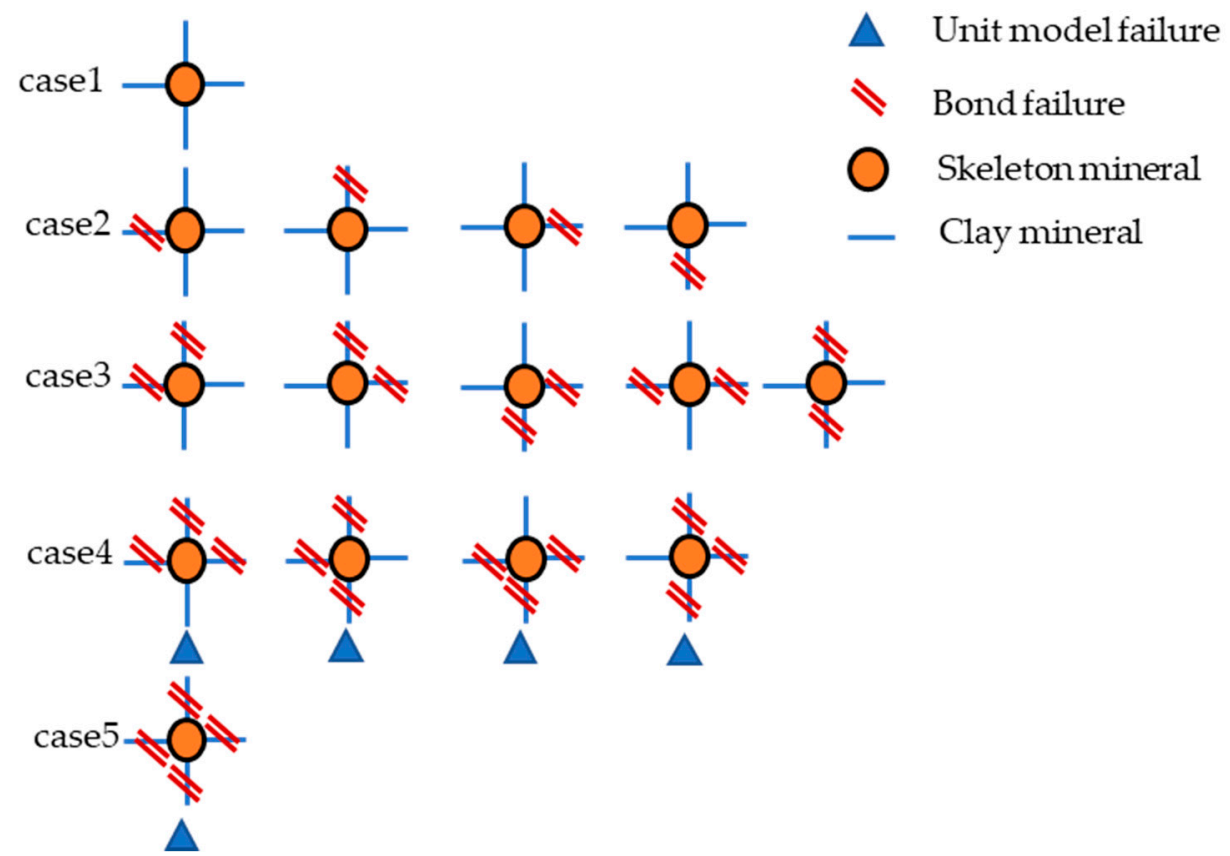

Figure 10. Different state of stripy unit models.

We can firstly analyze the failure probability of unit in the first two scale during renormalization process:

$$
P_{1}=4 P^{3}(1-P)+P^{4}
$$


where $P_{1}$ represents the unit failure probability in scale 1 , and $P$ represents the failure probability of mineral elements encountering water immersion. The failure probability on the right side of Equation (10) is derived from the five failure unit model states in Figure 10. According to the renormalization group theory, after one time of transformation, the accumulated failure probability in scale 2 is derived:

$$
P_{2}=4 P_{1}^{3}\left(1-P_{1}\right)+P_{1}^{4}
$$

After $n$ times of renormalization, the failure probability of red-bed soft rock in scale $n$ is derived:

$$
P_{n}=4 P_{n-1}^{3}\left(1-P_{n-1}\right)+P_{n-1}^{4}
$$

According to renormalization group theory, the solution of $P_{n+1}=P_{n}$ is corresponding to the red bed soft rock critical state under failure process.

According to $P_{n+1}=P_{n}$, we can derive Equation (13):

$$
P_{n}=4 P_{n}^{3}\left(1-P_{n}\right)+P_{n}^{4}
$$

Solving this equation, we can obtain 4 solutions $(0,1,-0.4$ and 0.8 respectively). $P_{n}^{*}=0.8$ is the only reasonable solution, and it means that during the renormalization process, the red-bed soft rock with stripy model has a critical strength reduction coefficient of 0.8 under long-term water corrosion.

In this section, we have calculated the critical strength reduction coefficients of redbed soft rocks with the granular and stripy unit models, and the results are 0.6 and 0.8 respectively. The results can be verified by long-term water saturation experiments.

\subsection{The Calculation for Critical State of Deterioration Induced by Stress}

Note that the deterioration process can also be induced by stress. Hence, this section is aimed at describing the stress-induced critical state of red-bed soft rocks.

We apply the granular unit model into the stress caused failure analysis, and we assume that the clay element will be damaged under stress. The failure probability obeys the Weibull Function [39]:

$$
f(x)= \begin{cases}\frac{k}{\lambda}(x / \lambda)^{k-1} \exp \left[-\left(\frac{x}{\lambda}\right)^{k}\right] & x>0 \\ 0 & x<0\end{cases}
$$

where $\lambda$ is the scale parameter and $k$ is the shape parameter.

When the stress $\sigma$ is applied into the rock, the failure probability of the clay mineral element can be calculated:

$$
P_{\alpha}=\int_{0}^{\alpha \sigma_{n}} f(\sigma) d \sigma=1-\exp \left[-\left(\frac{\alpha \sigma_{n}}{\lambda}\right)^{k}\right]
$$

where $\sigma_{n}$ is the ultimate strength of red-bed soft rock and $\alpha$ is the loading coefficient.

From Figures 11 and 12, we can find that the clay mineral elements may be destroyed under the stress $\alpha \sigma_{n}$ in point $\mathrm{c}$ and may also can be broken in the former loading process between $\left[c \alpha \sigma_{n}: \alpha \sigma_{n}\right]$, where $\mathrm{c}$ is a constant coefficient less than 1 . The conditional damage probability can be expressed as:

$$
P_{\alpha \mid c \alpha}=\frac{P\left(c \alpha \sigma_{n}<\sigma<\alpha \sigma_{n}\right)}{P\left(\sigma>c \alpha \sigma_{n}\right)}=\frac{P_{\alpha}-P_{c \alpha}}{1-P_{c \alpha}}
$$




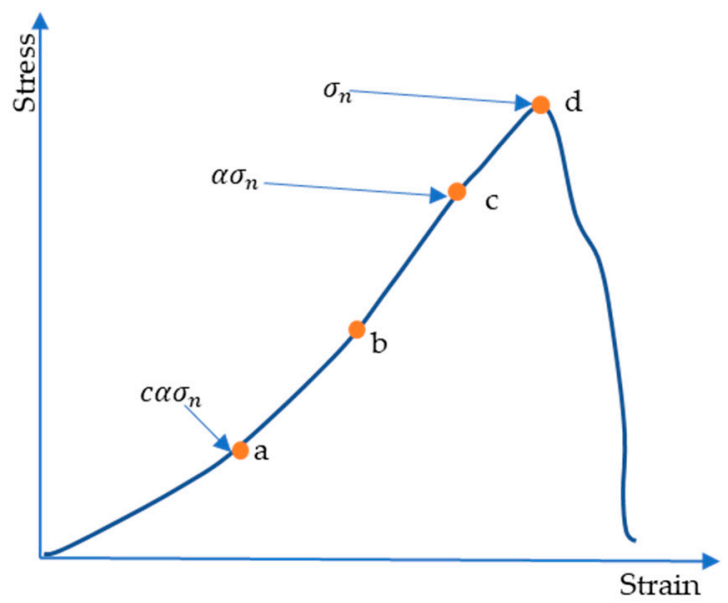

Figure 11. The loading points picked in stress-strain curve.

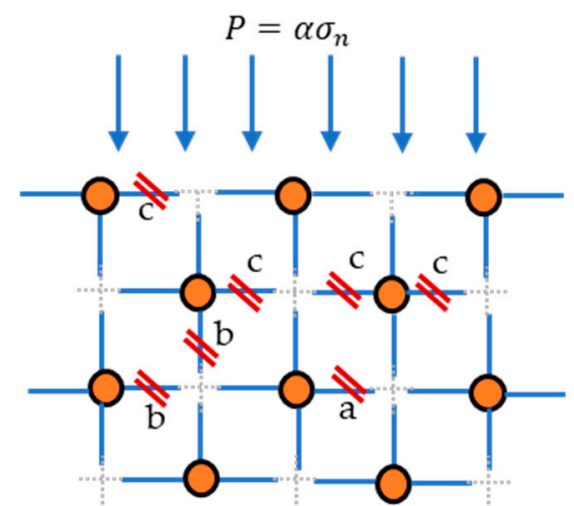

(a)

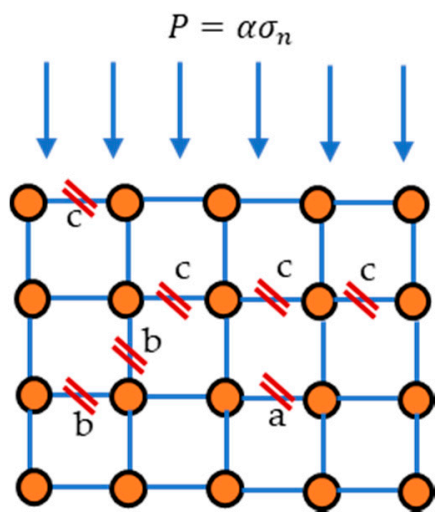

(b)

Figure 12. The stress induced failure states of two kinds of unit models. (a) Stripy model; (b) Granular model.

Submitting (16) into (17), the following relation is derived:

$$
P_{\alpha \mid c \alpha}=1-(1-A) \exp \left(c^{k}\right)
$$

Table 1 shows the failure probability of granular unit model in different cases. The event A represents the failure probability of clay mineral under stress $\alpha \sigma_{n}$, and event B represents the failure probability in the former loading process between $\left[c \alpha \sigma_{n}: \alpha \sigma_{n}\right]$.

Table 1. The failure probabilities of granular model.

\begin{tabular}{ccc}
\hline Number of Broken Parts & Case Combination & Failure Probability \\
\hline & $2 \mathrm{AA}(1-\mathrm{A})(1-\mathrm{A})$ & $2 P_{\alpha}^{2}\left(1-P_{\alpha}\right)^{2}$ \\
2 & $4 \mathrm{AB}(1-\mathrm{A})(1-\mathrm{A})$ & $4 P_{\alpha}\left[1-\left(1-P_{\alpha}\right) \times \exp \left(c^{k}\right)\right]\left(1-P_{\alpha}\right)^{2}$ \\
& $2 \mathrm{BB}(1-\mathrm{A})(1-\mathrm{A})$ & $2\left[1-\left(1-P_{\alpha}\right) \times \exp \left(c^{k}\right)\right]^{2}\left(1-P_{\alpha}\right)^{2}$ \\
\hline & $4 \mathrm{AAA}(1-\mathrm{A})$ & $4 P_{n}{ }^{3}\left(1-P_{n}\right)$ \\
$4 \mathrm{AAB} \times 3(1-\mathrm{A})$ & $12 P_{\alpha}{ }^{2}\left[1-\left(1-P_{\alpha}\right) \times \exp \left(c^{k}\right)\right]\left(1-P_{\alpha}\right)$ \\
4 & $12 P_{\alpha}\left[1-\left(1-P_{\alpha}\right) \times \exp \left(c^{k}\right)\right]^{2}\left(1-P_{\alpha}\right)$ \\
& $4 \mathrm{ABB} \times 3(1-\mathrm{A})$ & $4\left[1-\left(1-P_{\alpha}\right) \times \exp \left(c^{k}\right)\right]^{3}\left(1-P_{\alpha}\right)$ \\
\hline
\end{tabular}


Table 1. Cont.

\begin{tabular}{ccc}
\hline Number of Broken Parts & Case Combination & Failure Probability \\
\hline & AAAA & $P_{n}{ }^{4}$ \\
4 & AAAB $\times 4$ & $4 P_{\alpha}{ }^{3}\left[1-\left(1-P_{\alpha}\right) \times \exp \left(c^{k}\right)\right]$ \\
& ABBA $\times 6$ & $6 P_{\alpha}^{2}\left[1-\left(1-P_{\alpha}\right) \times \exp \left(c^{k}\right)\right]^{2}$ \\
& ABBB $\times 4$ & $4 P_{\alpha}\left[1-\left(1-P_{\alpha}\right) \times \exp \left(c^{k}\right)\right]^{3}$ \\
BBBB & {$\left[1-\left(1-P_{\alpha}\right) \times \exp \left(c^{k}\right)\right]^{4}$} \\
\hline
\end{tabular}

According to renormalization theory, after $\mathrm{n}$ times of iteration, the critical point can be found when $P_{n+1}=P_{n}$. The $P_{n+1}$ is expressed by Equation (18):

$$
\begin{gathered}
P_{n+1}=2 A A(1-A)^{2}+4 A B(1-A)^{2}+2 B B(1-A)^{2}+ \\
4 A A A(1-A)+12 A A B(1-A)+12 A B B(1-A)+ \\
4 B B B(1-A)+A A A A+6 A B B A+4 A B B B+B B B B
\end{gathered}
$$

Then the Equation (19) is obtained:

$$
\begin{gathered}
P_{n}=\left[1-\left(1-P_{n}\right) \times \exp \left(c^{k}\right)\right]^{4}+4\left[1-\left(1-P_{n}\right) \times \exp \left(c^{k}\right)\right]^{3}+ \\
\left(2+8 P_{n}-4 P_{n}^{2}\right)\left[1-\left(1-P_{n}\right) \times \exp \left(c^{k}\right)\right]^{2}+ \\
\left(4 P_{n}+4 P_{n}^{2}-4 P_{n}^{3}\right)\left[1-\left(1-P_{n}\right) \times \exp \left(c^{k}\right)\right]
\end{gathered}
$$

Equation (19) can be simply expressed as Equation (20):

$$
P_{n}=P_{n}(c, k)
$$

If the reasonable critical point can be derived, according to the critical point, the critical stress value can be determined. Analysis of the stripy model is similar, and because the object of this article is mainly for water induced deterioration, we save the analysis of stripy unit model herein.

\subsection{Experimental Schemes}

In Section 2.2, we established the granular and stripy renormalization unit models. The experimental process includes obtaining the meso-image of soft rocks by SEM technology, and the water immersion experiments for deriving the critical strength reduction coefficients. In this article, the red-bed soft rocks are chosen from Guangdong Province of China. Two kinds of soft rocks are light-grey silty mudstone and light-yellow silty mudstone respectively. The samples are in the size of $50 \mathrm{~mm} \times 100 \mathrm{~mm}$ according to ISRM methods. These samples are immersed for 1 month, 3 months, 6 months and 12 months respectively. Then the uniaxial strength of red-bed soft rocks are tested in Sun-Yat Sen University TAW soft rock testing system [40] (see Figure 13). 


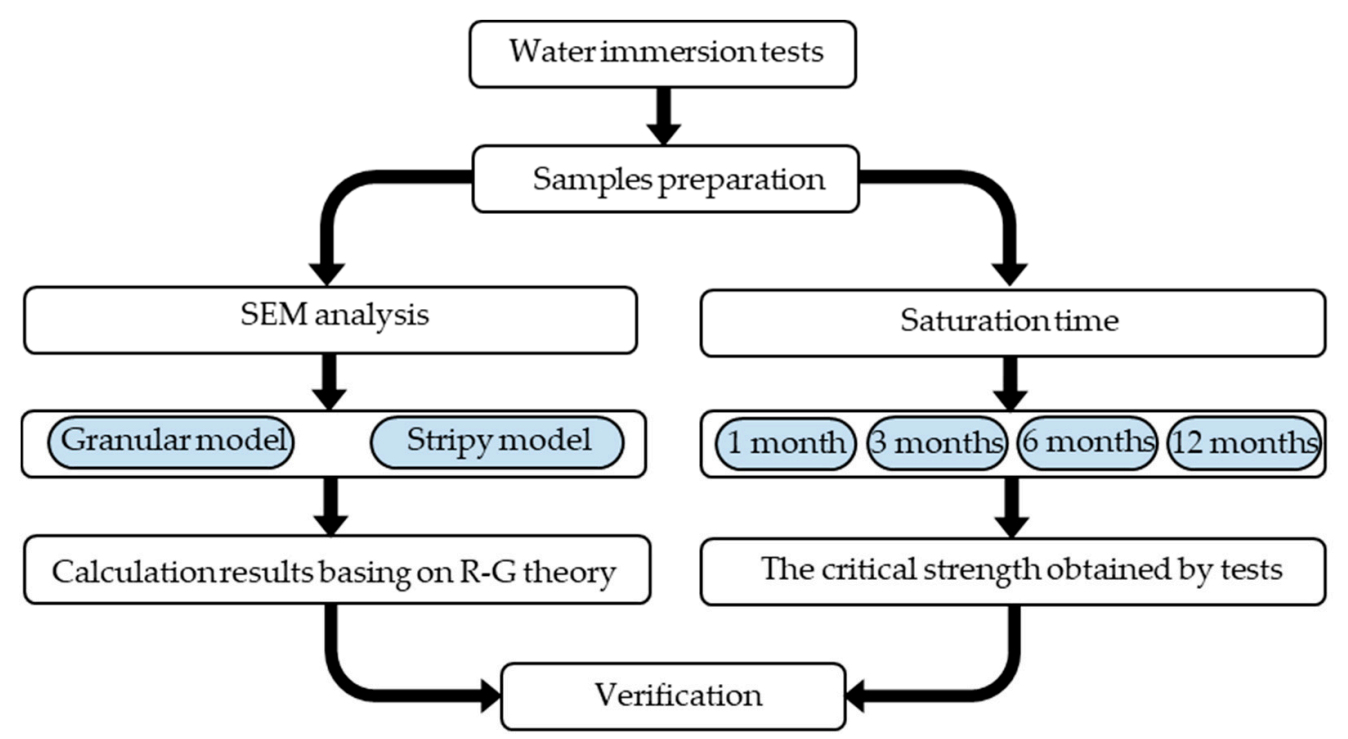

Figure 13. The schemes of experiments.

\section{Results and Discussion}

\subsection{The Meso-Structure Results of Red Bed Soft Rocks in SEM}

Figure 14 shows two kinds of soft rocks in this article; Figure 14a,b are the mesostructures of light-yellow silty mudstone under 3000 times magnification and 10,000 times magnification. Figure $14 \mathrm{c}, \mathrm{d}$ are the meso-structures of light-grey silty mudstone under 3000 times magnification and 10,000 times magnification, respectively. We can find that the meso-structures of red-bed soft rocks are self-similar in statistics. In the 10,000 times SEM images, the blue area is composed of clay minerals and the red area is composed of quartz minerals. The clay minerals can be simplified as stripy elements and the quartz can be simplified as skeleton elements.

According to Figure 14, we find that the ratio of clay minerals and skeleton minerals is 1:1 in light-yellow silty mudstone and 4:1 in light-grey silty mudstone. According to this statistical relation of minerals, we can apply the granular unit model into lightyellow silty mudstone and apply the stripy unit model into light-grey silty mudstone. The renormalization models and calculation process are different in two kinds of soft rocks; the calculation process basing on renormalization group theory has been conducted in Section 2.3 and we can subsequently derive the critical strength reduction coefficient of $60 \%$ in light-yellow silty mudstone and $80 \%$ in light-grey silty mudstone. The verification process is shown in the next section.

\subsection{The Strength Reduction Results of Water Immersion Experiments}

Table 2 has shown the uniaxial strengths of two kinds of red-bed soft rocks under different water immersion time. The clay minerals are prone to be broken causing an asymptotic deterioration in rock. Meanwhile, the strengths of red-bed soft rock will gradually decrease with the time. Figure 15 shows the strength reduction law of light-grey silty mudstone and light-yellow silty mudstone. 


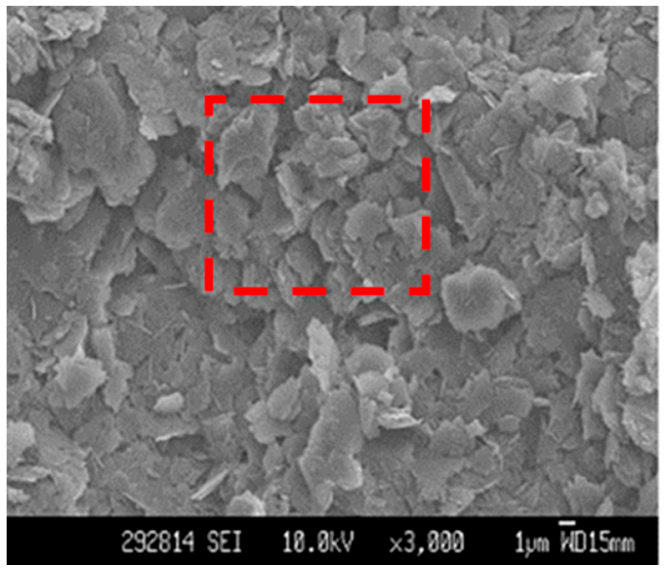

(a)

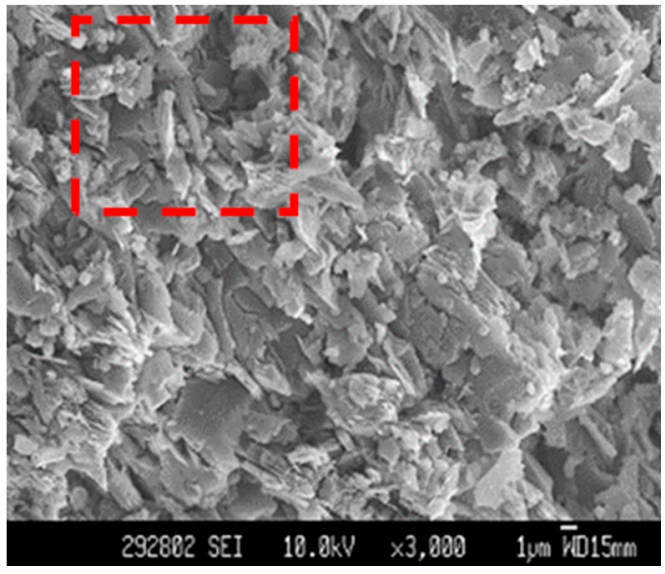

(c)

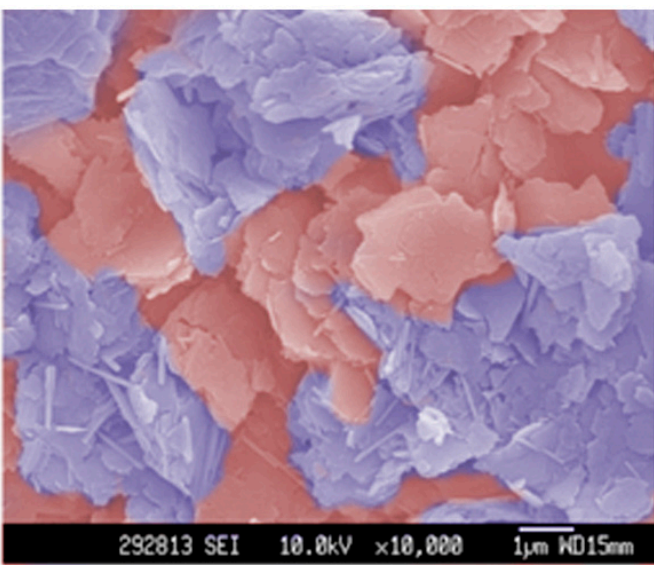

(b)

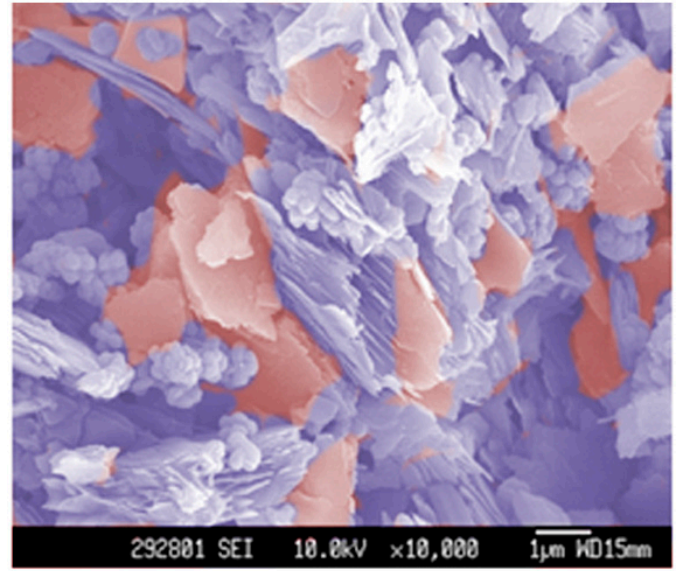

(d)

Figure 14. SEM images of red bed soft rocks under 3000 and 10,000 times magnification. (a) 3000 times magnification of light-yellow silty mudstone; (b) 10,000 times magnification of light-yellow silty mudstone; (c) 3000 times magnification of light-grey silty mudstone; (d) 10,000 times magnification of light-grey silty mudstone.

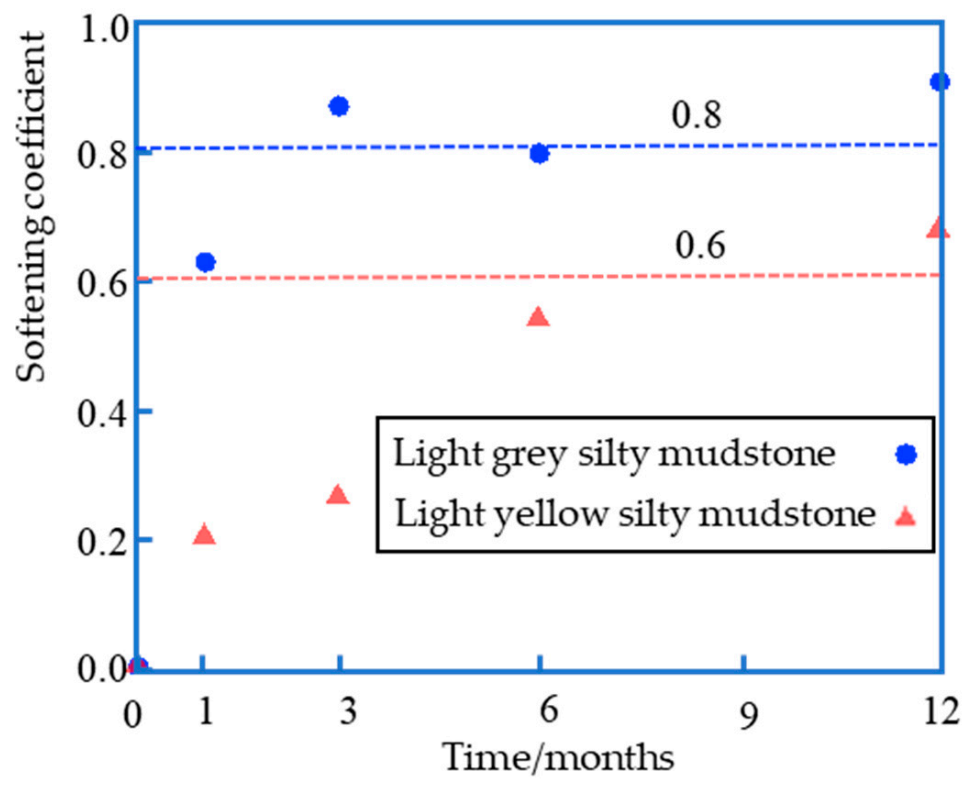

Figure 15. The strength reduction coefficients of soft rock. 
Table 2. The uniaxial strength of red bed soft rock under different time of saturation. (MPa).

\begin{tabular}{cccccc}
\hline Types & Initial State & One Month & Three Months & Six Months & Twelve Months \\
\hline light-grey silty mudstone & 4.51 & 1.68 & 0.59 & 0.92 & 0.42 \\
light-yellow silty mudstone & 1.45 & 1.16 & 1.07 & 0.67 & 0.47 \\
\hline
\end{tabular}

According to renormalization group theory, there is a critical point that distinguish stable and unstable state. In Figure 15, we can find that the strength reduction degree of light-grey silty mudstone become stable around 0.8 and the strength reduction degree of light-yellow silty mudstone become stable around 0.6. Therefore, we believe that the strength reduction ratio of 0.8 and 0.6 is the red bed soft rocks' critical strength reduction coefficient under long-term water corrosion in this article. Comparing the results with calculation results in Section 2.3, the granular unit model has a critical failure probability of 0.8 and the stripy unit model has a critical failure probability of 0.6 , which prove that the application of renormalization group theory in multi-scale deterioration issue of red-bed soft rock is effective.

For the water induced failure, we have given the calculation results and verified them by the experimental results. The water induced deterioration is a long-term process which is time-consuming when carrying out experiments. Therefore, the renormalization group theory herein is more effective. However, regarding the stress-induced failure, we find it difficult to give a precise solution when adopting renormalization group theory. The reason is that the unit model's failure probability is not the same during loading process, and the meso-structure's failure probability obey the Weibull Distribution. We have given the analytical solution of critical points for red-bed soft rock deterioration induced by stress in Section 2.4. Actually, the stress induced failure problem is more convenient when carrying out experiments.

\subsection{Discussion}

We have applied renormalization group theory into the study of critical state in redbed soft rocks' deterioration process. Note that the gradual damage process happens anytime when the clay minerals encountering water. In the meso-scale, tiny damage continues to accumulate. Although macro-crack cannot be observed at the beginning, the strength reduction can be regarded as another indicator of water induced deterioration. Finally, we can find the macro-cracks in the surface of red-bed soft rock after a long duration of water immersion (see Figure 16).

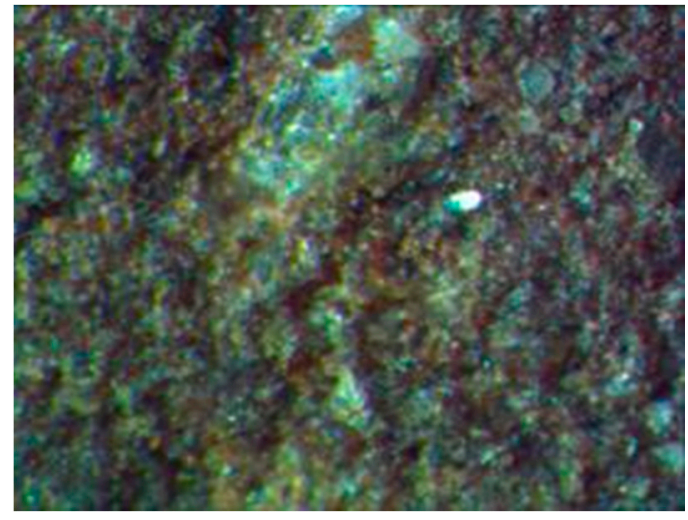

(a)

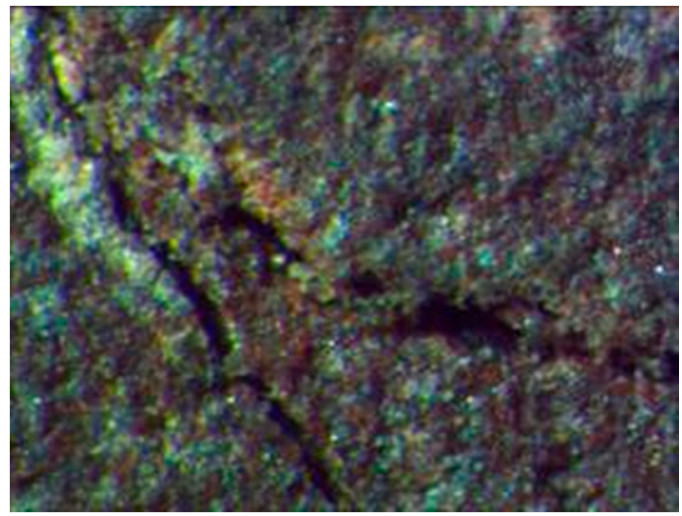

(b)

Figure 16. The virgin and failure state of light-yellow silty mudstone after water immersion. (a) Virgin state of light-yellow silty mudstone; (b) Failure state of light-yellow silty mudstone.

In the former sections we made assumptions that the damage process and renormalization process in red-bed soft rock system is disordered and randomly. However, the 
damage localization phenomenon was observed in Figure 16. It implies that the damage propagation process in meso-scale shows some specific directions which is violating our assumptions.

Actually, we can describe this phenomenon depending on the actual state of red-bed soft rocks. If there are some weaker structures in light-yellow silty mudstone, we can get a schematical water immersion model in Figure 17. The dotted line in Figure 17 represents some primitive weak elements. The water immersion induced failure can be divide into 4 steps: the virgin state, initial failure, subsequent failure and final state, respectively. In the virgin state, the damage is prone to appear at weak elements. Then the water corrosion will be localized in the first damaged network. With the modifying effect of primitive weak elements, the final crack states can be obtained and show some specific directions.

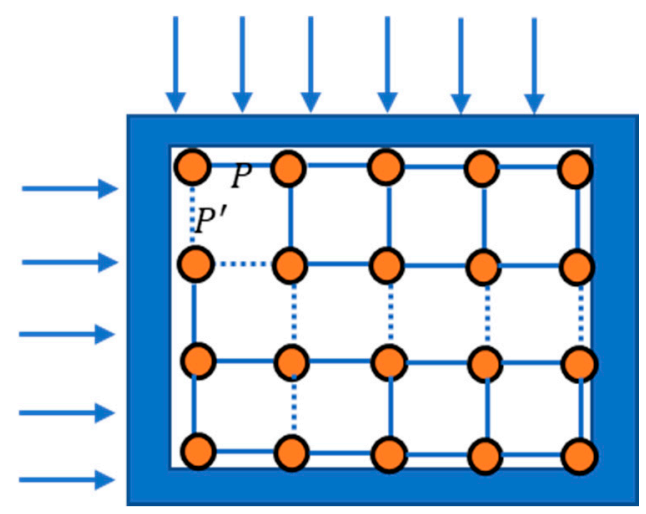

(a)

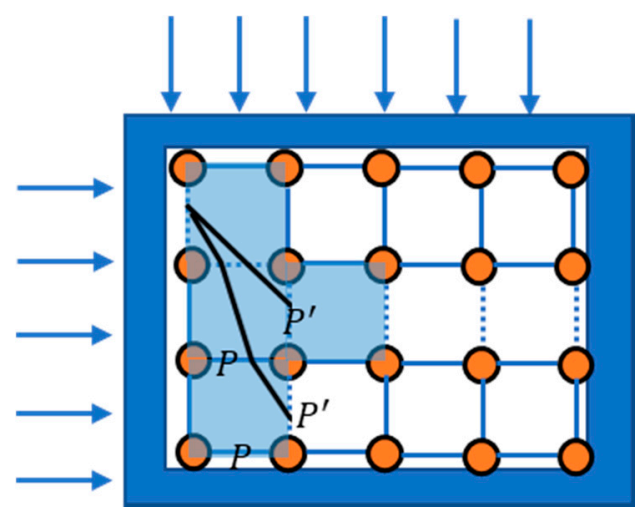

(c)

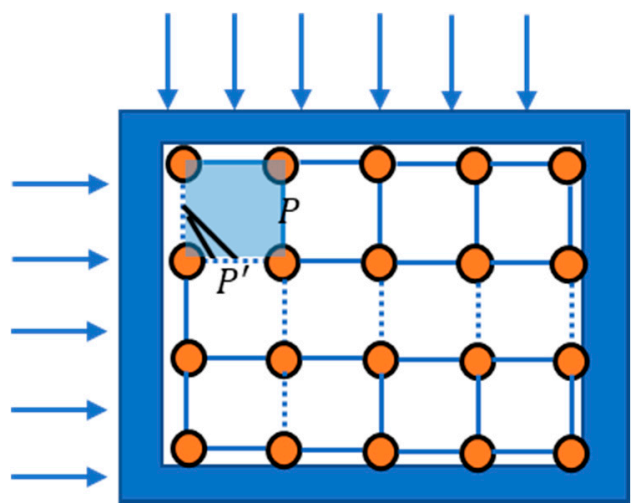

(b)

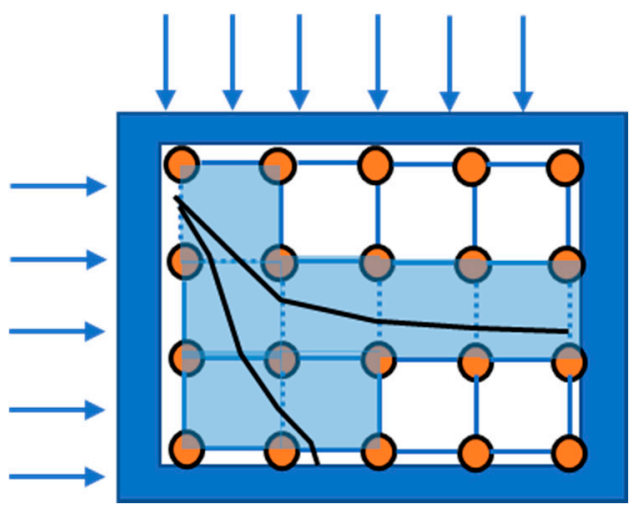

(d)

Figure 17. The schematical crack propagation process of red-bed soft rocks. (a) Virgin state; (b) Initial failure; (c) Subsequent failure (d) Final state.

The renormalization group theory is a method to deal with complex information in a disordered system evolution process. The link between critical point and the related indicator is different in others' analysis. Herein, we believe that the damage in unitmodel can be analyzed, and the related index is strength reduction coefficient in different saturation time. The corresponding result is easily used to predict water-induced failure. However, we find it difficult to further analyze the stress-induced failure. In this issue, Xue et al. [31] have studied the stress-induced failure evolution in hard rock, and gave a solution to predict the volume strain reverse point in stress-strain curve. The reason for their success in predicting the stress-induced failure in hard rock is that they picked another effective indicator (volume strain). However, this method is not applicable in red-bed soft rock. There are two reasons: (1) The deformation in soft rock is much larger than hard rock, and the volume strain reversing point may not represent the critical point in the deterioration process. (2) Except for the loading induced deformation, the creep deformation is also important to soft rock. 
Although the renormalization group theory can be applied in analyzing the state transition process, each specific issue needs to be studied separately. In different issues, we may focus on different properties of rock. Jiang et al. [33] established the connection between damage and unloading time in excavation induced rock failure. Xue et al. [32] studied the continuous progressive deformation in soft rock slopes, and they picked the deformation ratio as an indicator of damage propagation process. What I want to express is that the specific research result is more effective in its suitable field and the universal method is unrealistic.

\section{Conclusions}

To derive the critical, soften coefficient of soft rock under a saturation state, the sample test in laboratory is time consuming (more than 6 months). We have proved that the new method adopted in this paper is effective, which can theoretically derive the critical soften coefficient of red-bed soft rock in a convenient way. The following conclusions are derived:

(1) The tricky problem of coupling red-bed soft rock's multi-scale deterioration process is solved by renormalization group theory. The stress and water induced multiscale failure process is analyzed in a multi-scale perspective by ignoring the minor information in renormalization process.

(2) According to the meso-structure analysis in DEM images, two kinds of unit models (granular model and stripy model) are proposed. Basing on the proposed models, the specific analytical equations and their solutions are given. The prediction of long-term water immersion induced strength reduction is also calculated and verified by experiments.

(3) The method proposed in this article is applicable to red-bed soft rock engineering under the pre-work of meso-structure analysis.

Author Contributions: Conceptualization, Z.L. and C.Z.; methodology, C.X.; software, C.X.; validation, C.Z., Z.L. and C.Z.; formal analysis, Z.L. and F.Z.; investigation, C.X.; resources, C.X.; data curation, Z.L. and G.C.; writing-original draft preparation, C.X.; writing-review and editing, Z.L.; visualization, C.X.; supervision, C.Z.; project administration, C.Z.; funding acquisition, C.Z. All authors have read and agreed to the published version of the manuscript.

Funding: This research was funded by Ministry of Science and Technology of The People's Republic of China, grant numbers 2017YFC1501203 and 2017YFC1501201; National Natural Science Foundation of China, grant numbers 41530638 and 41977230; and Guangdong Science and Technology Department, grant numbers 2015B090925016 and 2016B010124007.

Institutional Review Board Statement: Not applicable.

Informed Consent Statement: Not applicable.

Data Availability Statement: The data presented in this study are available in article.

Acknowledgments: The authors would like to thank the anonymous reviewers for their very constructive and helpful comments.

Conflicts of Interest: The authors declare no conflict of interest.

\section{References}

1. Zhou, C.Y.; Yang, X.; Liang, Y.H.; Du, Z.C.; Liu, Z.; Huang, W.; Ming, W.H. Classification of red-bed rock mass structures and slope failure modes in South China. Geosciences 2019, 9, 273. [CrossRef]

2. Lai, J.; Wang, G.W.; Cao, J.T.; Xiao, C.W.; Wang, S.; Pang, X.J.; Dai, Q.Q.; He, Z.B.; Fan, X.Q.; Yang, L.; et al. Investigation of pore structure and petrophysical property in tight sandstones. Mar. Pet. Geol. 2018, 91, 179-189. [CrossRef]

3. Wang, H.; Wang, Y.-Y.; Yu, Z.-Q.; Li, J.-G. Experimental study on the effects of stress-induced damage on the microstructure and mechanical properties of soft rock. Adv. Civ. Eng. 2021, 2021. [CrossRef]

4. Liu, G.-Y.; Chen, Y.-L.; Du, X.; Azzam, R. A fractional viscoplastic model to predict the time-dependent displacement of deeply buried tunnels in swelling rock. Comput. Geotech. 2021, 129. [CrossRef]

5. Xu, T.; Xu, Q.; Tang, C.-A.; Ranjith, P.G. The evolution of rock failure with discontinuities due to shear creep. Acta Geotech. 2013, 8, 567-581. [CrossRef] 
6. Jing, W.; Wang, X.; Hao, P.; Jing, L.; Xue, W. Instability mechanism and key control technology of deep soft rock roadway under long-term water immersion. Adv. Civ. Eng. 2021, 2021. [CrossRef]

7. Zhou, C.Y.; Zhao, S.S.; Huang, W.; Li, D.X.; Liu, Z. Study on the stabilization mechanisms of clayey slope surfaces treated by spraying with a new soil additive. Appl. Sci. 2019, 9, 1245. [CrossRef]

8. Zhou, C.Y.; Ouyang, J.W.; Ming, W.H.; Zhang, G.H.; Du, Z.C.; Liu, Z. A stratigraphic prediction method based on machine learning. Appl. Sci. 2019, 9, 3553. [CrossRef]

9. Zhou, C.Y.; Li, D.X.; Liu, Z. Quantitative characterization of the aqua-dispersing nano-binder effects on the slip resistance of borrowed soil of a rock slope. Appl. Sci.-Basel 2019, 9, 3618. [CrossRef]

10. Xue, Y.; Ma, X.; Qiu, D.; Yang, W.; Li, X.; Kong, F.; Zhou, B.; Qu, C. Analysis of the factors influencing the nonuniform deformation and a deformation prediction model of soft rock tunnels by data mining. Tunn. Undergr. Space Technol. 2021, 109, 103769. [CrossRef]

11. Palchik, V. Influence of porosity and elastic modulus on uniaxial compressive strength in soft brittle porous sandstones. Rock Mech. Rock Eng. 1999, 32, 303-309. [CrossRef]

12. Zhao, Y.; Liu, H.-H. An elastic stress-strain relationship for porous rock under anisotropic stress conditions. Rock Mech. Rock Eng. 2012, 45, 389-399. [CrossRef]

13. Lollino, P.; Andriani, G.F. Role of brittle behaviour of soft calcarenites under low confinement: Laboratory observations and numerical investigation. Rock Mech. Rock Eng. 2017, 50, 1863-1882. [CrossRef]

14. Liu, Z.; Zhou, C.; Li, B.; Zhang, L.; Liang, Y. Effects of grain dissolution-diffusion sliding and hydro-mechanical interaction on the creep deformation of soft rocks. Acta Geotech. 2020, 15, 1219-1229. [CrossRef]

15. Nicolas, A.; Poirier, J.P. Crystalline Plasticity and Solid State Flow in Metamorphic Rocks; Wiley: Hoboken, NJ, USA, 1976.

16. Boioli, F.; Carrez, P.; Cordier, P.; Devincre, B.; Marquille, M. Modeling the creep properties of olivine by 2.5-dimensional dislocation dynamics simulations. Phys. Rev. B 2015, 92, 014115. [CrossRef]

17. Eriksson, R.; Schatz, T. Rheological properties of clay material at the solid/solution interface formed under quasi-free swelling conditions. Appl. Clay Sci. 2015, 108, 12-18. [CrossRef]

18. Okubo, S.; Fukui, K.; Hashiba, K. Development of a transparent triaxial cell and observation of rock deformation in compression and creep tests. Int. J. Rock Mech. Min. Sci. 2008, 45, 351-361. [CrossRef]

19. Takemura, T.; Oda, M.; Kirai, H.; Golshani, A. Microstructural based time-dependent failure mechanism and its relation to geological background. Int. J. Rock Mech. Min. Sci. 2012, 53, 76-85. [CrossRef]

20. Urai, J.L.; Spiers, C.J.; Zwart, H.J.; Lister, G.S. Weakening of rock salt by water during long-term creep. Nature 1986, 324, 554-557. [CrossRef]

21. Xu, J.; Haque, A.; Gong, W.; Gamage, R.P.; Dai, G.; Zhang, Q.; Xu, F. Experimental study on the bearing mechanisms of rock-socketed piles in soft rock based on micro X-ray CT analysis. Rock Mech. Rock Eng. 2020, 53, 3395-3416. [CrossRef]

22. Leuthold, J.; Gerolymatou, E.; Vergara, M.R.; Triantafyllidis, T. Effect of compaction banding on the hydraulic properties of porous rock: Part I-experimental investigation. Rock Mech. Rock Eng. 2021. [CrossRef]

23. Yang, X.J.; Wang, J.M.; Zhu, C.; He, M.C.; Gao, Y. Effect of wetting and drying cycles on microstructure of rock based on SEM. Environ. Earth Sci. 2019, 78, 10. [CrossRef]

24. Tao, M.; Zhao, H.; Momeni, A.; Wang, Y.; Cao, W. Fracture failure analysis of elliptical hole bored granodiorite rocks under impact loads. Theor. Appl. Fract. Mech. 2020, 107, 102516. [CrossRef]

25. Chen, Y.; Yang, Y.G.; Gao, F.; Zhang, X.X. Researches on damage evolution and acoustic emission characteristics of rocks. Adv. Civ. Eng. 2018, 2018, 7. [CrossRef]

26. Shuang, H.-Q.; Li, S.-G.; Liu, L.; Chen, G.-F.; Song, K.-I. Use of acoustic emission for the detection of brittle rock failure under various loading rates. Adv. Civ. Eng. 2018, 2018, 5735139. [CrossRef]

27. Wang, Y.; Zhang, D.; Hu, Y.Z. X-ray computed tomography characterization of soil and rock mixture under cyclic triaxial testing: The effects of confining pressure on meso-structural changes. Environ. Earth Sci. 2019, 78, 1. [CrossRef]

28. Komine, H. Simplified evaluation for swelling characteristics of bentonites. Eng. Geol. 2004, 71, 265-279. [CrossRef]

29. Arnould, M. Discontinuity networks in mudstones: A geological approach-Implications for radioactive wastes isolation in deep geological formations in Belgium, France, Switzerland. Bull. Eng. Geol. Environ. 2006, 65, 413-422. [CrossRef]

30. Risnes, R.; Haghighi, H.; Korsnes, R.I.; Natvik, O. Chalk-fluid interactions with glycol and brines. Tectonophysics 2003, 370, 213-226. [CrossRef]

31. Xue, L.; Qi, M.; Qin, S.; Li, G.; Li, P.; Wang, M. A potential strain indicator for brittle failure prediction of low-porosity rock: Part II-theoretical studies based on renormalization group theory. Rock Mech. Rock Eng. 2015, 48, 1773-1785. [CrossRef]

32. Xue, L.; Qin, S.; Li, P.; Li, G.; Oyediran, I.A.; Pan, X. New quantitative displacement criteria for slope deformation process: From the onset of the accelerating creep to brittle rupture and final failure. Eng. Geol. 2014, 182, 79-87. [CrossRef]

33. Jiang, Q.; Li, J.; Luo, Z.; Xu, X.; Assefa, E.; Deng, H. Study on the time-lag failure of sandstone with different degrees of unloading damage. Period. Polytech.-Civ. Eng. 2019, 63, 206-214. [CrossRef]

34. Wei, S.; Shen, J.; Yang, W.; Li, Z.; Di, S.; Ma, C. Application of the renormalization group approach for permeability estimation in digital rocks. J. Pet. Sci. Eng. 2019, 179, 631-644. [CrossRef]

35. Irayani, Z.; Fauzi, U.; Viridi, S.; Latief, F.D.E. Calculation of anisotropy permeability from 3D tomographic images using renormalization group approaches and lattice Boltzmann method. J. Pet. Explor. Prod. Technol. 2019, 9, 889-897. [CrossRef] 
36. Tuller, M.; Or, D. Hydraulic functions for swelling soils: Pore scale considerations. J. Hydrol. 2003, 272, 50-71. [CrossRef]

37. Wilson, K.G. The renormalization group: Critical phenomena and the Kondo problem. Rev. Mod. Phys. 1975, 47, 773-840. [CrossRef]

38. Liu, Z.; Zhou, C.; Zhu, F.; Zhang, L. Critical criterion for microstructure evolution of soft rocks in softening process. Rock Soil Mech. 2011, 32, 661-666. [CrossRef]

39. Cao, W.; Zhao, M.; Liu, C. Study on the model and its modifying method for rock softening and damage based on weibull random distribution. Chin. J. Rock Mech. Eng. 2004, 23, 3226-3231.

40. Zhou, C.; Deng, Y.; Tan, X.; Liu, Z.; Shang, W.; Zhan, S. Experimental research on the softening of mechanical properties of saturated soft rocks and application. Chin. J. Rock Mech. Eng. 2005, 24, 33-38. 